\title{
AN INVESTIGATION OF THE EFFECT OF THE HUB MOTOR WEIGHT ON VEHICLE SUSPENSION AND PASSENGER COMFORT
}

\author{
ABDUSSALAM ALI AHMED ${ }^{1}$, MASOOD A. MASOOD ${ }^{2}$, AMHIMMID Q ALMABROUK ${ }^{3}$, \\ ZAYAD M. SHEGGAF ${ }^{4}$, MOHAMED MOHAMED KHALEEL ${ }^{5}$ \& MOHAMED BELRZAEG ${ }^{6}$ \\ ${ }^{1,6}$ Mechanical and Industrial Engineering Department, Bani Waleed University, Bani Waleed/Libya \\ ${ }^{2,4}$ College of Technical Sciences, Bani Waild, Libya \\ ${ }^{3}$ Department of Mechatronics, Higher Institute of Engineering Technology Bani Walid/Libya \\ ${ }^{5}$ Department of Aeronautical Engineering, College of Civil Aviation-Misurata, Misuratal Libya
}

ABSTRACT
One of the most critical components in a vehicle is the suspension system, as it is responsible for stability and handling in
the vehicle structure and thus ensuring the passenger's comfort because it absorbs shocks caused by different road
conditions and prevents them from reaching the passengers' seats. A passive suspension system with eight degrees of
freedom was investigated and evaluated in two cases in this research: the first case using standard wheels the second case
using hub motors. To complete this work, the equations of motion of the suspension system were shown then the full
model construction was implemented using Matlab. It is known that the hub motor weight is bigger than the standard
wheel weight that's why this work obtain a little bad effect on vehicle performance when using hub motors, an active
suspension system that can improve vehicle performance and ride comfort is recommended.
KEYWORDS: Suspension System, Hub Motor, Vehicle \& Ride Comfort

Received: Jul 06, 2021; Accepted: Jul 26, 2021; Published: Aug 13, 2021 ; Paper Id: IJMPERDOCT20214

\section{NOMENCLATURE}

\begin{tabular}{|c|c|}
\hline W1, W2, W3, W4 & The wheel hub motor weight in $\mathrm{Kg}$ \\
\hline $\mathbf{W}$ & The sprung weight is expressed in $\mathrm{Kg}$ \\
\hline Wp & The weight of the passenger seat in $\mathrm{Kg}$ \\
\hline S1, S2, S3, S4 & The spring stiffness in $\mathrm{N} / \mathrm{m}$ on each side \\
\hline b1, b2, b3,b4 & The damper coefficient in N.s/m on each side \\
\hline $\mathbf{A}$ & The vehicle's half-width in $\mathrm{m}$ \\
\hline B, C & Location of the C.G. from the front and back axles, respectively in $\mathrm{m}$ \\
\hline St & The wheel stiffness is measured in $\mathrm{N} / \mathrm{m}$ \\
\hline Kp & Stiffness $(\mathrm{N} / \mathrm{m})$ of the passenger seat \\
\hline bp & The damping coefficient of the passenger seat (in Ns/m) \\
\hline $\mathbf{X p}, \mathbf{Z p}$ & Seat location with relation to the sprung mass's centre of gravity $(\mathrm{m})$ \\
\hline
\end{tabular}




\begin{tabular}{|l|l|}
\hline $\boldsymbol{\theta}$ & Displacement of the sprung mass pitch in radian \\
\hline \multicolumn{1}{|c|}{$\emptyset$} & The radian displacement of the sprung mass roll \\
\hline Q1, Q2, Q3, Q4 & Each side's actuator force in $\mathrm{N}$ \\
\hline Y1, Y2, Y3, Y4 & The profile of the road (road input) at each wheel in $\mathrm{m}$ \\
\hline Y11, Y22, Y33, Y44 & The displacement of the wheel on each side in $\mathrm{m}$ \\
\hline Ix & Rolling mass moment of inertia in $\left(\mathrm{kg}-\mathrm{m}^{2}\right)$ \\
\hline $\mathbf{I z}$ & Roll's mass moment of inertia in $(\mathrm{kg}-\mathrm{m} 2)$ \\
\hline
\end{tabular}

\section{INTRODUCTION}

When you consider your vehicle's performance, you typically focus on its horsepower, torque, and acceleration, overlooking more significant factors. Specialists, the most critical of which is the suspension system of the car. Following the development of the four-stroke internal combustion engine, engineers focused on the vehicle's suspension system, which is responsible for maximizing the friction between the car's wheels and the road surface. This is to ensure the car's stability when driving, particularly on difficult roads, and to ensure the comfort of passengers inside the vehicle. Suspension systems are not required if the road is fully flat and without bumps, although this is rarely the case, and it is worth mentioning that the road does contain certain flaws. It will undoubtedly have an effect on your vehicle's wheels (1).

The purpose of this article is to construct and analyse a simple suspension vehicle model that can be used for simulation in the Matlab Simulink environment. Numerous contributions analyse simply the whole passive suspension model and then use it for analysis, synthesis, and finally for stability and ride comfort validation via simulations. While our model is not explicitly specified here for the control and synthesis problems, the use of a comprehensive vehicle suspension model with a passenger is critical for simulation in a wide variety of vehicle sectors and applications.

One of the suspension system's objectives is to isolate the vehicle's body from road disturbances in order to provide a comfortable ride, while the other functions include ensuring good road holding, giving appropriate handling, and supporting the vehicle's static weight (2).

In today's suspensions, hydraulic dampers (alternatively referred to as shock absorbers) and springs are used to absorb bumps, limit body motions of the vehicle during acceleration, braking, and turning, and keep tires in contact with the road surface. These goals often contradict each other. Luxury vehicles are great for absorbing bumps and delivering comfortable driving, but handling has a tendency to pitch and dive in acceleration and braking, and to be lean on the body (or "sway") think Town of Lincoln (3).

Multi-body dynamics have long been used by the automotive industry to design and refine suspension. In order to test iteratively multiple input factors for car suspension performance before the adoption of new optimisation approaches. Till the present performance targets were fulfilled, the analysis will be carried out. Optimization of the design, parametric tests and sensitivity analysis were challenging, if not impossible. This traditional optimization approach, generally followed by prototype testing, can be difficult and time-consuming for completely sophisticated systems. With the 
introduction of numerous optimization methods and advancing computer technology, the design process has been accelerated to achieve optimal values and studies on the influence of design aspects to acquire the minimum/maximum of an objective function subject to limits. These restrictions incorporate practical considerations into the design process (4).

A key concern arose with the arrival of hub engines in the field of electric vehicles: 'What does the additional wheel weight of a hub engine affect the safety and comfort of a car. The unsprung mass of moving power from the motor carrier to the wheels might be as large as $50 \mathrm{~kg}$ or more per rolling wheel. Most suspension research in conventional cars has been carried out(5). There was no serious analysis of the increased mass. The unsprung mass should not exceed $20 \%$ of sprung mass according to several recommendations (6),in the existing road vehicle fleet, this ratio is not exceeded, and there is no solid evidence to support it.

The impact of wheel hub motors on vehicle ride comfort was tested on the highway with the VW Lupo 3L. The experimental results are used in validating the SimMechanics software model of a comprehensive automobile simulation. It is intended to examine the impact of hub motors on the comfort and road maintenance of a battery-electric car. It was also used to investigate possible improvements to ride comfort and road holding by optimizing suspension systems or using an electromagnetic suspension system controlled by a skyhook control or a hybrid control technique (7).

Note: This study is an extension of a study conducted on the same topic in reference number (17).

\section{WHEEL HUB MOTOR TECHNOLOGY}

The wheel hub motor (also known as an in-wheel motor, wheel motor, or hub motor) is an electric motor that is built into a wheel's hub and drives it directly.

Because there have been numerous studies on the interest in the use of a hub motor drive system as electric automobiles. Related items started appearing on the market. A hub wheel motor drive system that places or develops engines adjacent to the wheel can also be used for various conveys, such as electric bicycles, two-wheeled electric motor chairs and four-wheeled electric vehicles (8-9).

The primary components of the wheel hub motor and the unsprung assembly, which were both built by Protean Electric, are depicted in figures 1 and 2, respectively. Protean Electric is an automotive technology innovator and a worldleading developer of hub motors and future propulsion systems. Protean Electric is headquartered in the United Kingdom. Protean Electric, which was established in 2008, has invested more than one million engineering person-hours in the development and validation of their Protean Drive wheel hub motor technology. 


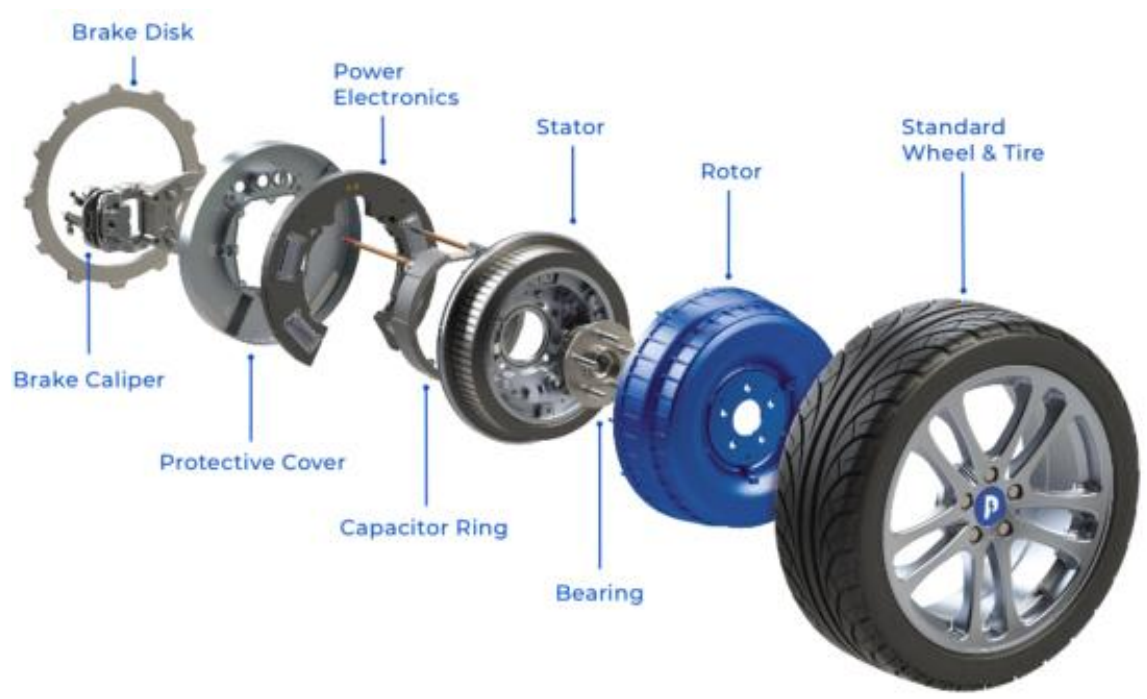

Figure 1: Wheel Hub Motor Components.
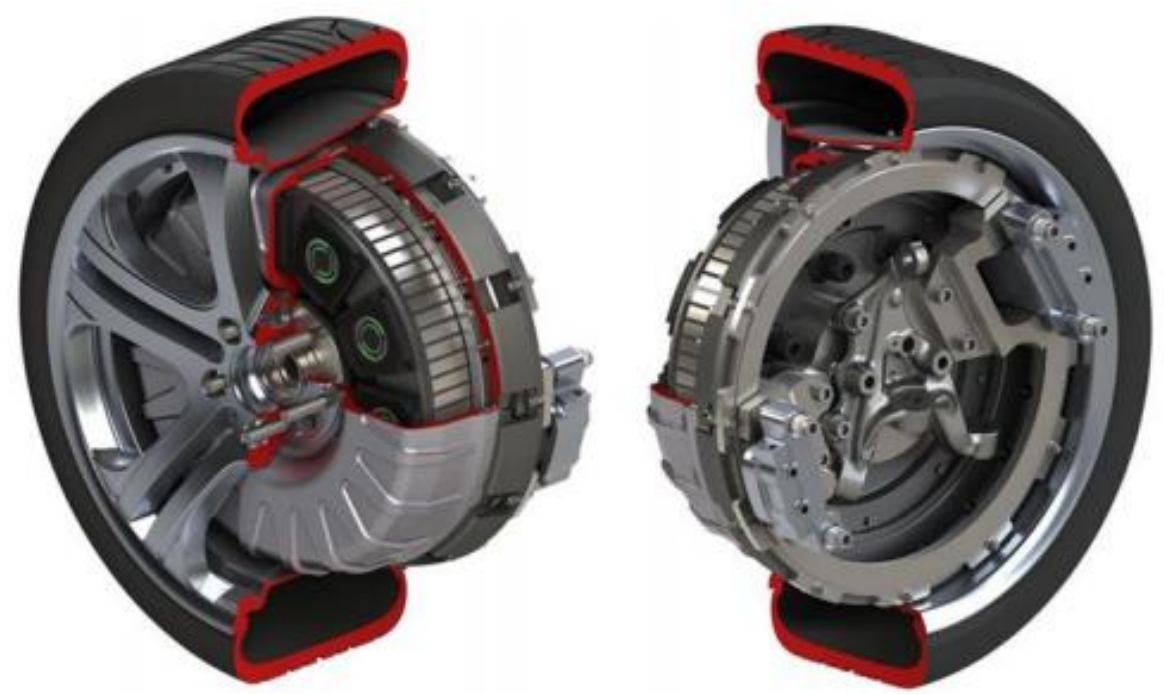

Figure 2: Front-Left Corner of a Protean/Brabus E-Class (Unsprung Assembly).

\section{SYSTEM AND MATHEMATICAL MODEL}

A whole vehicle model with eight degrees of freedom is analyzed for the purposes of analysis and evaluation. Figure 3 displays a full vehicle suspension model, which includes the passenger seat, sprung mass (the component of the car supported by springs), and unsprung mass (the component of the car that is not supported by springs) (the mass of the wheel assembly). Wheel stiffness has been substituted with its equivalence, and wheel damping has been completely omitted in this calculation. To simulate the suspension, wheel, and passenger seat, linear springs in parallel with dampers are used in conjunction with dampers. The sprung mass has three degrees of freedom (bounce, pitch, and roll) in the vehicle model, but the passenger seat and four unsprung masses each have 1 DOF in the vehicle model. 


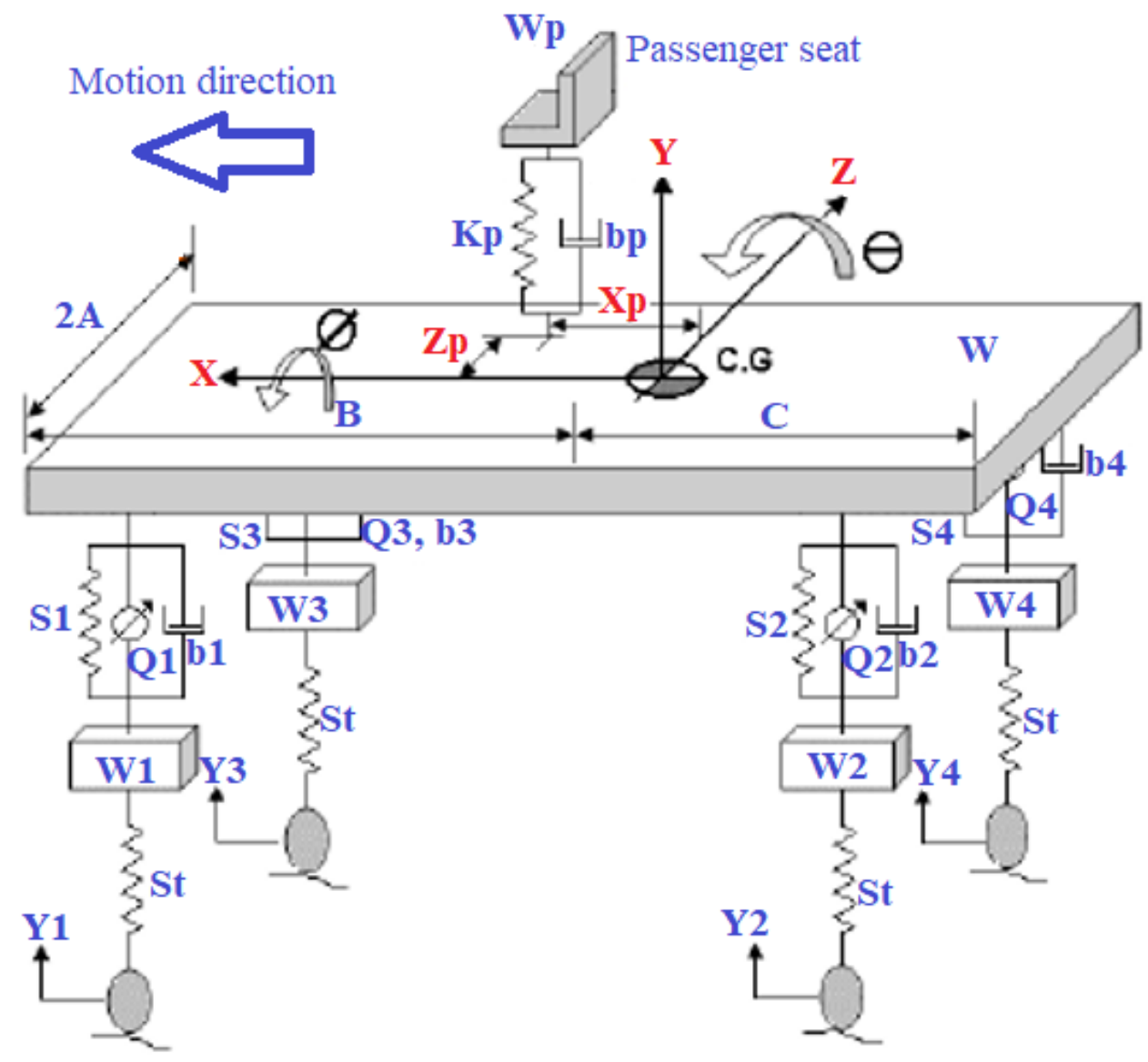

Figure 3: Full Vehicle Suspension Model.

W1andW3 is both left-side and left-front unsprung mass, whereas W2 \& W4 respectively rear left-hand and righthand unsprung masses these four unleash masses are employed as standard wheels, and in other times as hub wheel motors. In this paper, these four unsprung masses are used. Table 1 and Table 2 show the specifications of the wheel hub motors for both front and rear wheels.

Table 1: The Motor Specs Utilized at the Unsprung Mass on the front Left and Right Sides, Respectively.

\begin{tabular}{|l|c|}
\hline \multicolumn{1}{|c|}{ Company and Hub Motor Type } & ELAPHE LTD. (S400) \\
\hline Additional weight & $17.5 \mathrm{~kg}$ \\
\hline Maximum torque & $400 \mathrm{Nm}$ \\
\hline Maximum power & $45 \mathrm{KW}$ \\
\hline Top speed & $1570 \mathrm{rpm}$ \\
\hline $\begin{array}{l}\text { Continuous power } \\
\text { (liquid cooling) }\end{array}$ & $25 \mathrm{~kW}$ \\
\hline
\end{tabular}


Table 2: The Motor Specs Utilized in the Rear Left and Rear Right Unsprung Masses, Respectively.

\begin{tabular}{|l|c|}
\hline \multicolumn{1}{|c|}{ Company and Hub Motor Type } & ELAPHE LTD. (M70) \\
\hline Additional weight & $25 \mathrm{~kg}$ \\
\hline Maximum torque & More than 700 Nm \\
\hline Maximum power & $79 \mathrm{KW}$ \\
\hline Top speed & $1665 \mathrm{rpm}$ \\
\hline $\begin{array}{l}\text { Continuous power } \\
\text { (liquid cooling) }\end{array}$ & $52 \mathrm{~kW}$ (liquid cooling) \\
\hline
\end{tabular}

Based on Newton's second law of motion, the equations of motion for the system represented in figure 3 can be stated as follows:

$$
\begin{array}{r}
W \ddot{Y}+S 1(Y-B \theta+A \emptyset-Y 1)-A b 1(\dot{Y}-B \dot{\theta}+A \dot{\emptyset}-\dot{Y} 1)+A S 2(Y+C \theta+A \emptyset-Y 2)+A b 2(\dot{Y}+C \dot{\theta}+A \dot{\emptyset}- \\
\dot{Y} 2)-A S 3(Y-B \theta-A \emptyset-Y 3)-A b 3(\dot{Y}-B \dot{\theta}+A \dot{\emptyset}-\dot{Y} 3)-A S 4(Y+C \theta-A \emptyset-Y 4)-A b 4(Y+C \dot{\theta}-A \dot{\emptyset}-\dot{Y} 4)+ \\
Z p K p(Y p-Y-X p \theta-Z p \emptyset)+Z p b p(\dot{Y} p-Z \dot{Y}-X p \dot{\theta}-Z p \dot{\emptyset})-A Q 1-A Q 2+A Q 3+A Q 4=0
\end{array}
$$

(1)

$$
\begin{gathered}
I x \ddot{\emptyset}+A S 1(Y-B \theta+A \emptyset-Y 1)-b 1(\dot{Y}-B \dot{\theta}+A \dot{\emptyset}-\dot{Y} 1)+S 2(Y+C \theta+A \emptyset-Y 2)+b 2(\dot{Y}+C \dot{\theta}+A \dot{\emptyset}- \\
\dot{Y} 2)+S 3(Y-B \theta-A \emptyset-Y 3)+b 3(\dot{Y}-a B+A \dot{\varnothing}-\dot{Y} 3)+S 4(Y+C \theta-A \emptyset-Y 4)+b 4(\dot{Y}+C \dot{\theta}-A \dot{\emptyset}-\dot{Y} 4)- \\
K p(Y p-Y-X p \theta-Z p \emptyset)-b p(\dot{Y} p-\dot{Y}-X p \dot{\theta}-Z Y p \dot{\emptyset})-Q 1-Q 2+Q 3+Q 4=0 \\
W \ddot{Y}+K p(Y p-Y-X p \theta-Z p \emptyset)+b p(\dot{Y} p-\dot{Y}-X p \dot{\theta}-Z p \dot{\varnothing})=0 \\
I z \ddot{\theta}+B S 1(Y-B \theta+A \emptyset-Y 1)-B b 1(\dot{Y}-B \dot{\theta}+A \dot{\emptyset}-\dot{Y} 1)+C S 2(Y+C \theta+A \emptyset-Y 2)+C b 2(\dot{Y}+b C+ \\
A \dot{\emptyset}-\dot{Y} 2)+B S 3(Y-B \theta-A \emptyset-Y 3)+B b 3(\dot{Y}-B \dot{\theta}+A \dot{\emptyset}-\dot{Y} 3)+C S 4(Y+C \theta-A \emptyset-Y 4)+C b 4(\dot{Y}+b C-A \dot{\emptyset}- \\
\dot{Y} 4)+X p K p(Y p-Y-X p \theta-Z p \emptyset)+X p b p(\dot{Y} p-\dot{Y}-X p \dot{\theta}-Z p \dot{\varnothing})+B Q 1-C Q 2+B Q 3-C Q 4=0
\end{gathered}
$$

(4)

$$
\begin{aligned}
& W 1 \ddot{Y} 11-S 1(Y-B \theta+A \emptyset-Y 11)-b 1(\dot{Y}-B \dot{\theta}+A \dot{\varnothing}-\dot{Y} 11)+S t(Y 11-Y 1)+Q 1=0 \\
& W 2 \ddot{Y} 22-S 2(Y+C \theta+A \emptyset-Y 22)-b 2(\dot{Y}+C \dot{\theta}+A \dot{\emptyset}-\dot{Y} 22)+S t(Y 22-Y 2)+Q 2=0 \\
& W 3 \ddot{Y} 33-S 3(Y-B \theta-A \emptyset-Y 33)-b 3(\dot{Y}-B \dot{\theta}+A \dot{\varnothing}-\dot{Y} 33)+S t(Y 33-Y 3)+Q 3=0 \\
& W 4 \ddot{Y} 44-S K 4(Y+C \theta-A \emptyset-Y 33)-b 4(\dot{Y}+C \dot{\theta}-A \dot{\varnothing}-\dot{Y} 44)+S t(Y 44-Y 4)+Q 4=0
\end{aligned}
$$

\section{ROAD PROFILE (Y1, Y2, Y3, and Y4)}

As illustrated in figure 4, the road bump at each wheel assumed a single profile in this study, and the subsystem Simulink model of the input bump road $Y i$ was created.

Figure 5 depicts a single bump road input $(Y i)$ that is used to express the road state and conditions, as well as to verify the created system. This road bump is referred to as a road profile or a road disturbance, and it is set to reach a bump height of $0.05 \mathrm{~m}$. 


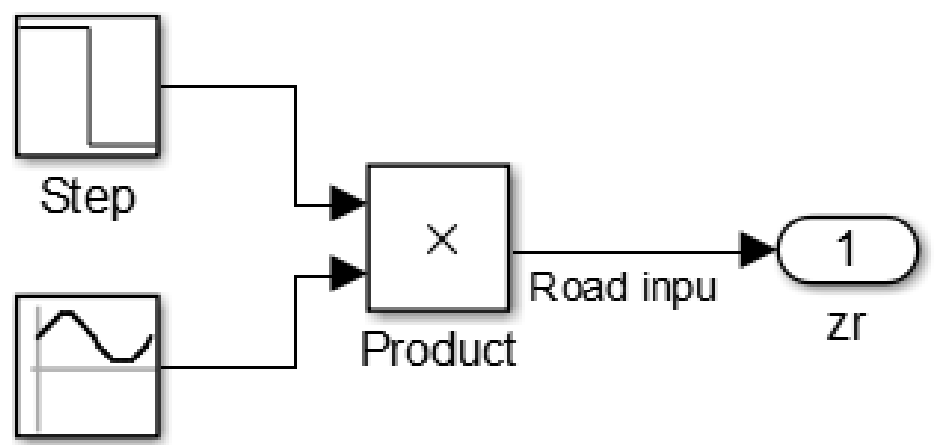

Sine Wave

Figure 4: Subsystem Model of the Bumpy Road Input.

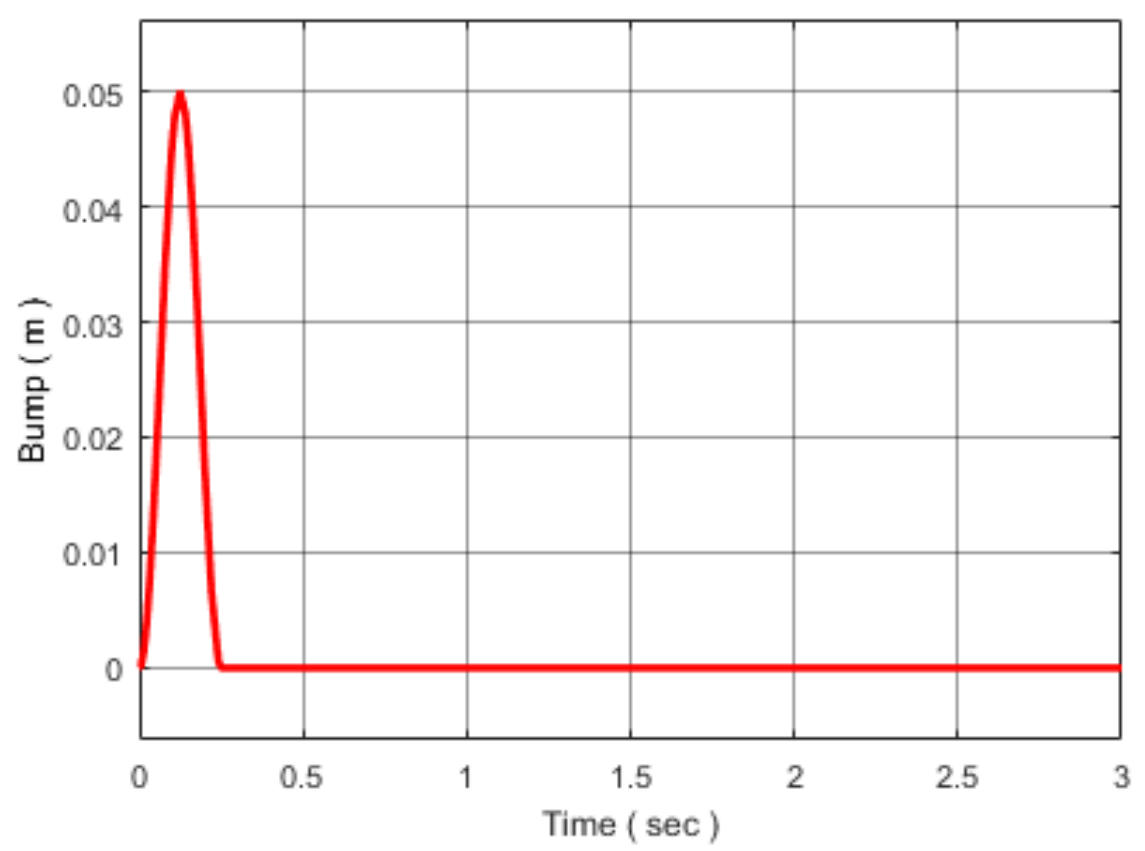

Figure 5: Bumpy Road Input Signal at Each Wheel.

The Matlab/Simulink software was used to create the Simulink model of the Suspension System shown in figure 6, which was implemented according to the free-body diagram of the full vehicle suspension system in figure 3 and the eight equations of motion mentioned above, as well as taking into account bumpy road input signals at each wheel. 


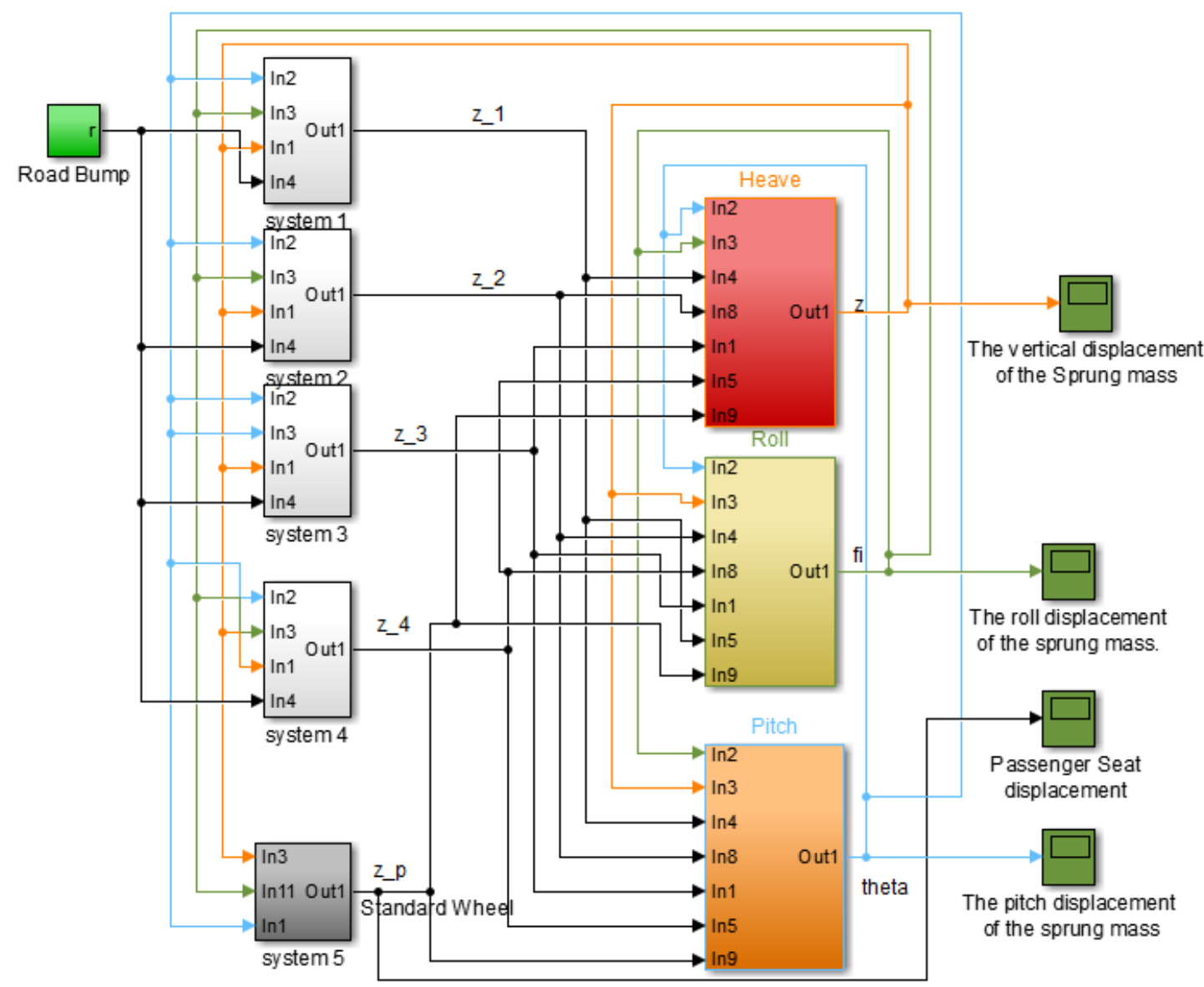

Figure 6: Full Representation of the Suspension System in Simulink.

\section{SIMULATION RESULTS AND DISCUSSIONS}

The proposed scheme for suspension system has been simulated using MATLAB/SIMULINK under certain condition and parameters. Figure 3 shows the full suspension system used in this paper that has been used in the simulation, where Y1, Y2, Y3 and Y4 are the vertical displacement of road at each wheel, whileW1and W3 are Front left and front right side wheel weightin kilograms respectively, while W2 \& W4 are Rear left and rear right side wheel weightin kilograms respectively. The output response has been simulated for change in road profile of $0.05 \mathrm{~m}$.

As previously stated in this work, the purpose of this investigation is to analyse the performance of the vehicle in two scenarios, the first case is the use of four standard wheels, while in the second case four wheel hub motors were used.

The outputs of the model system depicted in Figure 6 are four major output metrics that clearly demonstrate the vehicle's performance, which is clearly relevant to ride comfort and road handling. The vertical displacement of the sprung mass, the roll displacement of the sprung mass, the displacement of the Passenger Seat, and the pitch displacement of the sprung mass are the four components that give an indication of the vehicle performance.

Figures 7-10 show the selected four output parameters of the system, all figures showed that the vehicle performance was better duringthe use of standard wheels compared to the wheel hub motors, which means that the use of the in-wheels had a negative impact in a simple way, especially in Figure 9 which shows the sprung mass roll 
displacement. The reason for the negative impact on the performance of the studied suspension system in the case of using hub motors is the increase in the mass of these wheels, which has led to a decrease in passenger comfort and road handling.

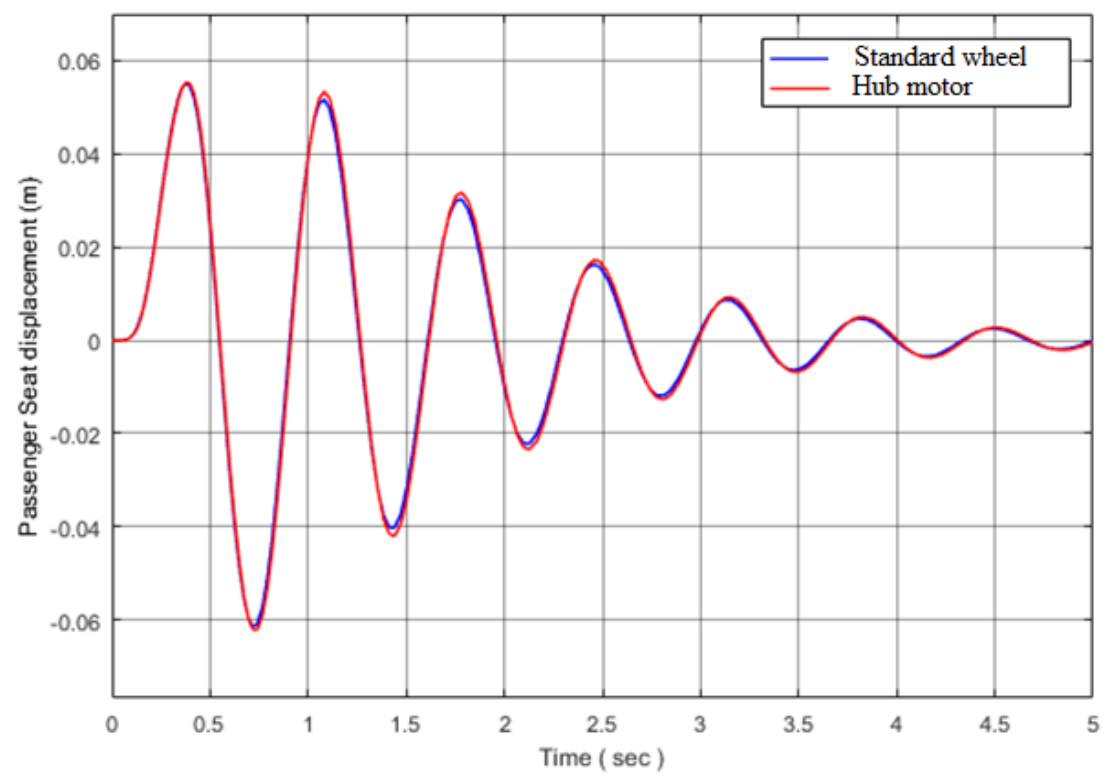

Figure 7: Passenger Seat Displacement.

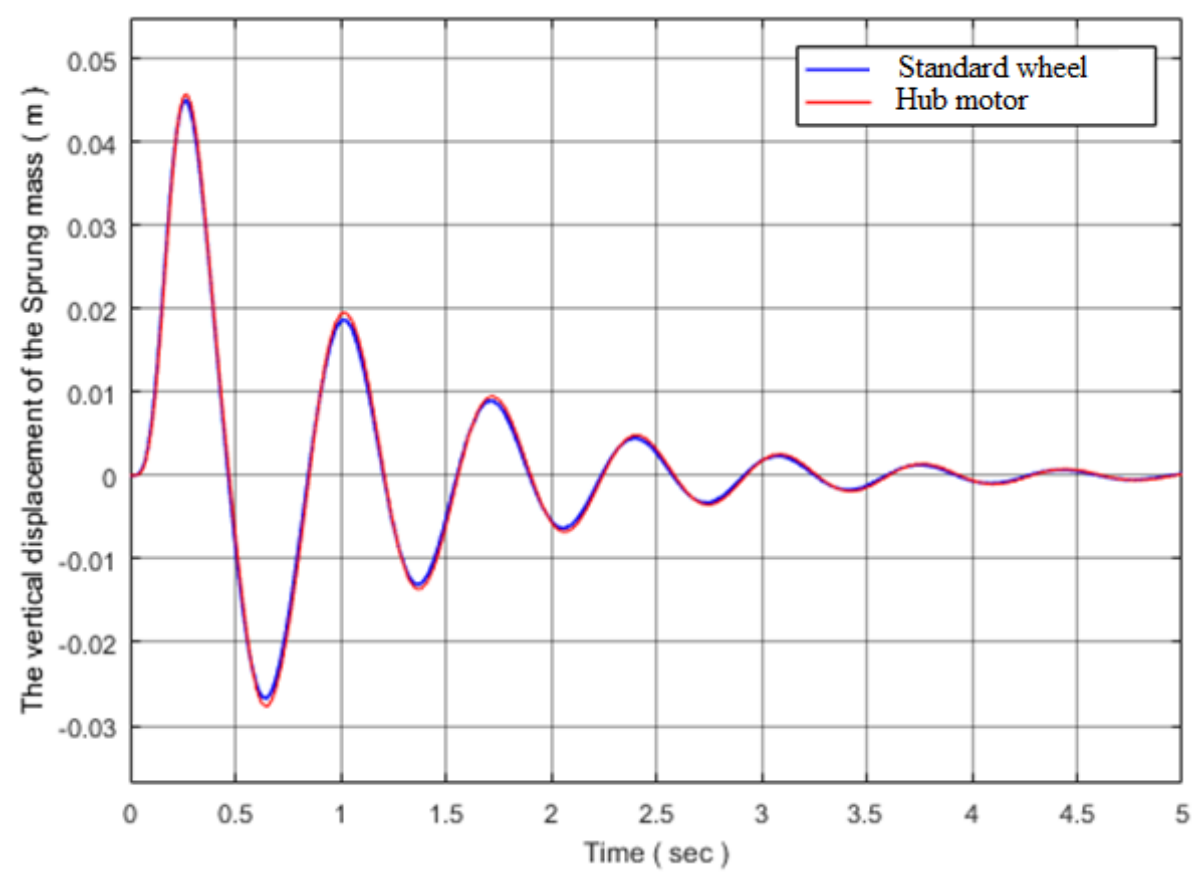

Figure 8: The Sprung Mass's Vertical Displacement. 


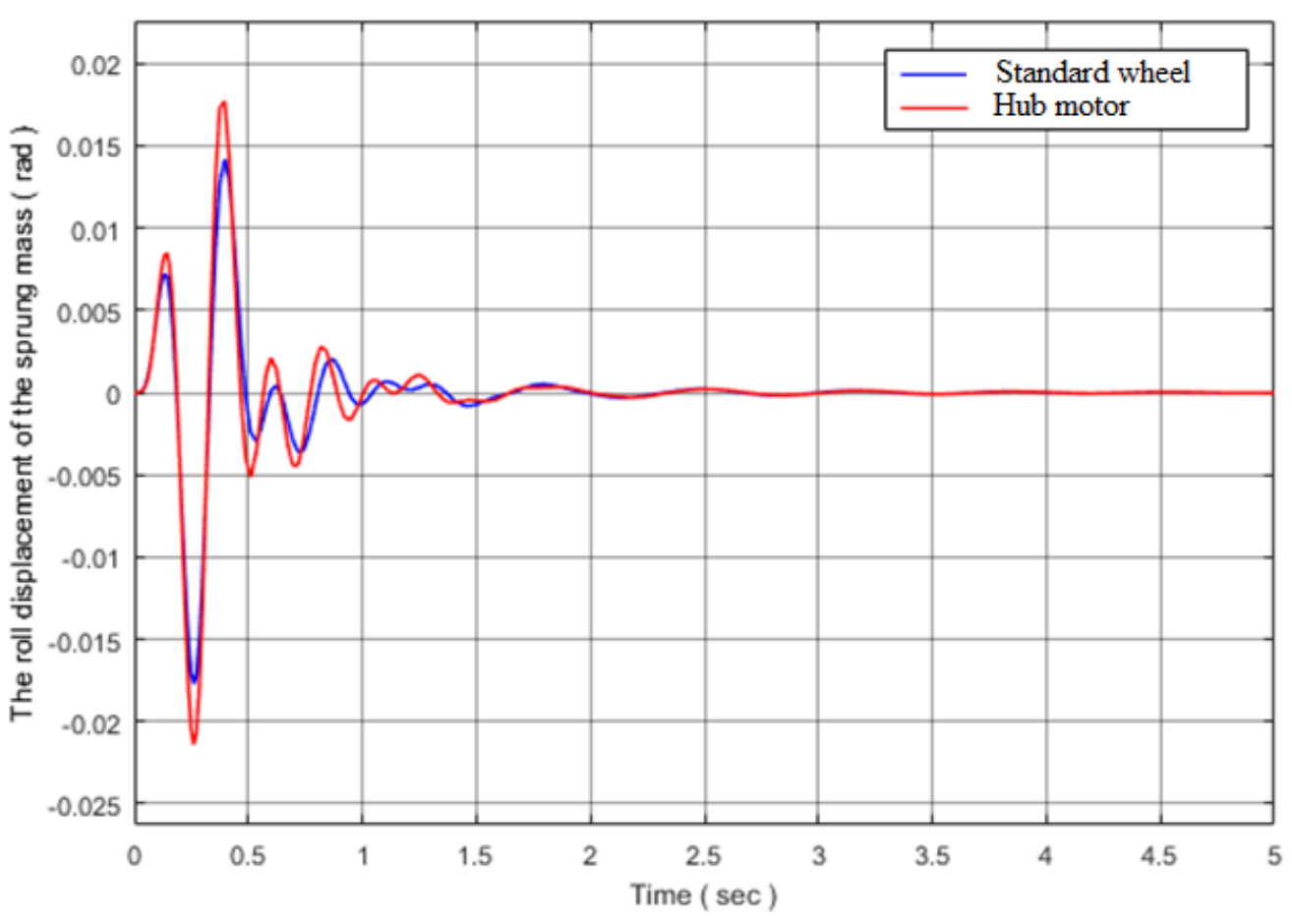

Figure 9: The Sprung Mass's Roll Displacement.

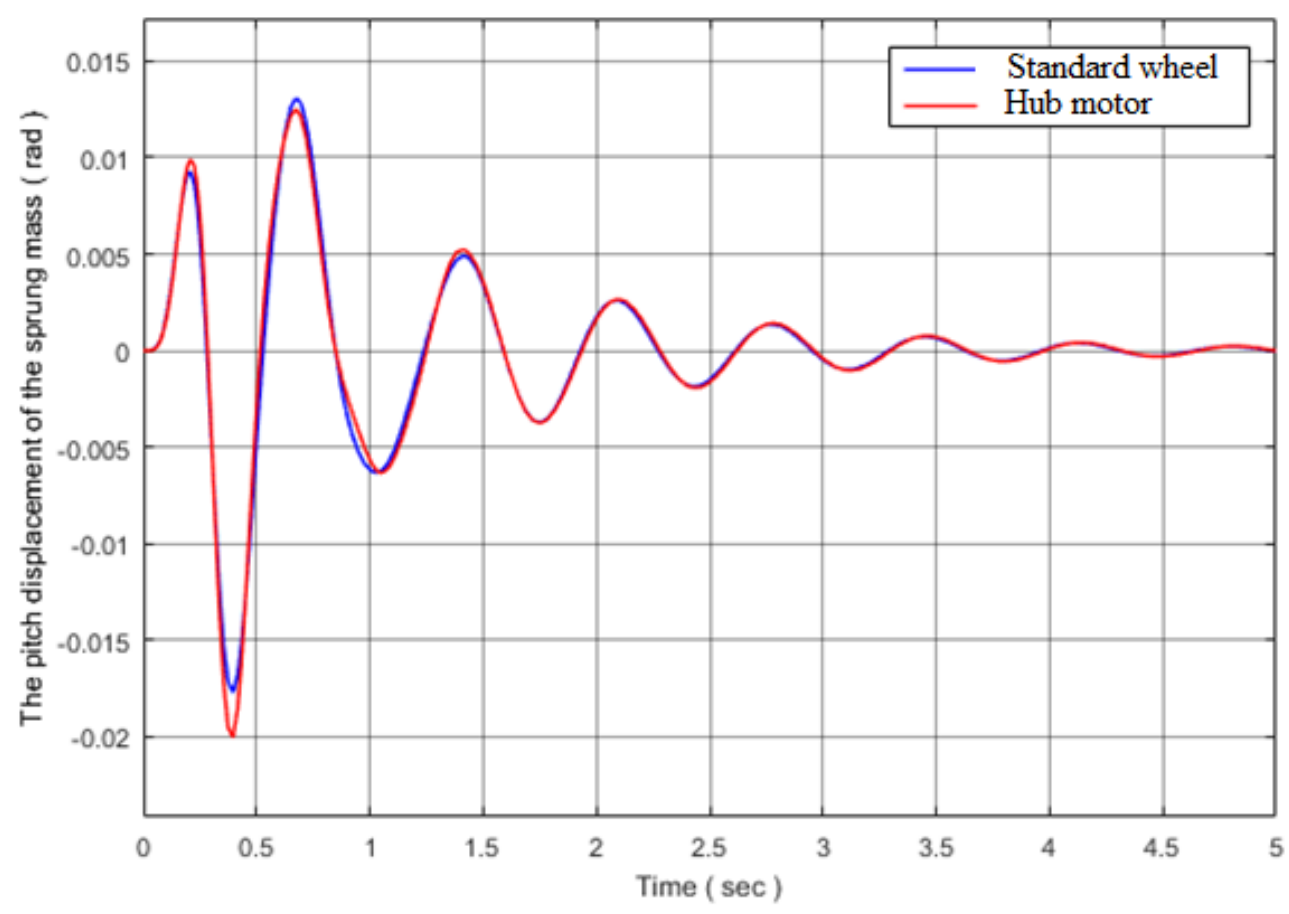

Figure 10: The Sprung Mass's Pitch Displacement.

\section{CONCLUSIONS}

In this paper, a performance of full vehicle suspension system is evaluated, where the system was studied evaluated in two cases, the first case when using standard wheels for the vehicle, while the second case when using wheelhub motors. Standard wheels provide a positive effect on suspension system performance over purely wheel hub motors. Based on the 
simulation results, it is obvious that increasing the amount of sprung mass has a negative effect, particularly in the pitch and roll displacements of the sprung mass.

\section{REFERENCES}

1. "How Car Suspensions Work", auto.howstuffworks.com, Retrieved 2020-08-20. Edited.

2. Rajesh Rajamani, Vehicle Dynamics and Control, Springer publications, Second edition, 2012.

3. Abdussalam Ali Ahmed and Başar Özkan, "Analysis of effect of in-wheel electric motors mass on passive and active suspension systems", ARPN Journal of Engineering and Applied Sciences, Vol. 10, No. 14, August 2015.

4. Baumal, A.E., McPhee, J.J., and Calamai, P.H., "Application of Genetic Algorithms to the Design Optimization of an Active Vehicle Suspension System", Computer Methods in Applied Mechanics and Engineering, Vol. 163, pp. 87-94. 1998.

5. W.E. Misselhorn, "Verification of hardware-in-loop as a valid testing method for suspension development," Masters Degree dissertation, 2005, University of Pretoria, South Africa.

6. R.Q. Riley, “Automobile ride, handling and suspension design with implications for low mass vehicles, ” Copyright 1999-2005, Robert Q. Riley Enterprises.

7. Vos, R., Besselink, I. J. M., \& Nijmeijer, H. (2010). Influence of in-wheel motors on the ride comfort of electric vehicles. In Proceedings of the 10th International Symposium on Advanced Vehicle Control (AVEC10), 22-26 August 2010, Loughborough, United Kingdom (pp. 835-840).

8. K. Sone, M. Takemoto, S. Ogasawara, K. Takezaki, and H. Akiyama, A ferrite PM in-wheel motor without rare earth materials for electric city commuters, IEEE Trans. Magn., vol. 48, no. 11, pp. 2961-2964, Nov. 2012

9. J. Lee, J. Kim, and B. Woo, Optimal design of inwheel motor for an E-bike, in Proc. 2016 IEEE Transportation Electrification Conference and Expo (ITEC Asia-pacific), pp.441-443, 2016.

A. A. Ahmed and O. S. M. Jomah, "Modeling and Control of Car Active Suspension System Using a Neural Network-based Controller and Linear Quadratic Regulator Controller," 2020 IEEE 2nd International Conference on Electronics, Control, Optimization and Computer Science (ICECOCS), 2020, pp. 1-6, doi: 10.1109/ICECOCS50124.2020.9314426.

10. T. Suzuki, F. Chauvicourt and H. Fujimoto, "High-Bandwidth Suspension Resonance Analysis of In-Wheel Motor Vehicle Using Multibody Dynamics," 2021 IEEE International Conference on Mechatronics (ICM), 2021, pp. 1-6, doi: 10.1109/ICM46511.2021.9385653.

A. A. Ahmed and A. F. Saleh Alshandoli, "Using Of Neural Network Controller And Fuzzy PID Control To Improve Electric Vehicle Stability Based On A14-DOF Model," 2020 International Conference on Electrical Engineering (ICEE), 2020, pp. 16, doi: 10.1109/ICEE49691.2020.9249784.

11. Ying MA. 2013. Zhaoxiang DENG and Dan XIE, Control of the Active Suspension for In-Wheel Motor. Journal of Advanced Mechanical Design Systems and Manufacturing. 7(4).

12. Abdolvhab Agharkakly, Ghobad, Shafiei Sabet, Armin Barouz. 2012. simulation and analysis of passive and active suspension system using quarter car model for deferent road profiles. International Journal of Engineering Trends and Technology. 3(5).

13. Sayel M. Fayyad. 2012. Construing control system for active suspension system, contemporary engineering sciences. 5(4): 189-200.

14. B.L.J. Gysen, J.L.G. Janssen, J.J.H. Paulides and E.A. Lomonova. Design apsects of an active electromagnetic suspension system for automotive applications. IEEE transactions on industry applications, 45(5):1589 - 1597, 2009. 
15. Anil Shirahatti, P.S.S. Prasad, Pravin Panzade, M.M. Kulkarni, Optimal design of passenger car suspension for ride and road holding, J. Braz. Soc. Mech. Sci. \& Eng. 30 (1) • Mar 2008, https://doi.org/10.1590/S1678-58782008000100010.

16. L. Hott et al., "Ride Blending Control for AWD Electric Vehicle with In-Wheel Motors and Electromagnetic Suspension," 2020 IEEE Vehicle Power and Propulsion Conference (VPPC), 2020, pp. 1-5, doi: 10.1109/VPPC49601.2020.9330946.

17. Z. Li, Z. Qi, Z. Dong, Z. Deng and S. Ren, "An optimal control design of independent suspension based on Adams for a four inwheel-motor drive electric vehicle," 2012 19th International Conference on Mechatronics and Machine Vision in Practice (M2VIP), 2012, pp. 517-520.

18. Y. Tang, J. J. H. Paulides, I. J. M. Besselink, F. Gardner and E. A. Lomonova, "Indirect drive in-wheel system for HEV/EV traction," 2013 World Electric Vehicle Symposium and Exhibition (EVS27), 2013, pp. 1-9, doi: 10.1109/EVS.2013.6915011.

19. C. Chen, Y. Cheng and F. Meng, "Optimum Design of a Novel In-Wheel Suspension of the Electric Wheel," 2019 IEEE $3 r d$ International Conference on Green Energy and Applications (ICGEA), 2019, pp. 106-110, doi: 10.1109/ICGEA.2019.8880784.

20. Y. Ma, C. Lu, H. Zhao and M. Hao, "Nonlinear model predictive slip control based on vertical suspension system for an inwheel-motored electric vehicle," 2017 29th Chinese Control And Decision Conference (CCDC), 2017, pp. 4967-4972, doi: 10.1109/CCDC.2017.7979375.

21. Y. Yu, L. Zhao and C. Zhou, "Influence of Rotor-Bearing Coupling Vibration on Dynamic Behavior of Electric Vehicle Driven by In-Wheel Motor," in IEEE Access, vol. 7, pp. 63540-63549, 2019, doi: 10.1109/ACCESS.2019.2916554.

22. G. S. G. Ravikanth and C. Sujatha, "Dynamic modeling and simulation of a three-wheeled hub motor vehicle," 2017 IEEE Transportation Electrification Conference (ITEC-India), 2017, pp. 1-5, doi: 10.1109/ITEC-India.2017.8333849.

23. C. J. Ifedi, B. C. Mecrow, J. D. Widmer, G. J. Atkinson, S. T. M. Brockway and D. Kostic-Perovic, "A high torque density, direct drive in-wheel motor for electric vehicles," 6th IET International Conference on Power Electronics, Machines and Drives (PEMD 2012), 2012, pp. 1-6, doi: 10.1049/cp.2012.0254.

24. B. Xu, C. Xiang, Y. Qin, P. Ding and M. Dong, "Semi-Active Vibration Control for in-Wheel Switched Reluctance Motor Driven Electric Vehicle With Dynamic Vibration Absorbing Structures: Concept and Validation," in IEEE Access, vol. 6, pp. 60274-60285, 2018, doi: 10.1109/ACCESS.2018.2875197.

25. J. Zhao, Y. Ma, H. Zhao, Y. Cui and H. Chen, "PID slip control based on vertical suspension system for in-wheel-motored electric vehicles," 2018 Chinese Control And Decision Conference (CCDC), 2018, pp. 1126-1131, doi: 10.1109/CCDC.2018.8407298.

26. Y. Luo and D. Tan, "Study on the Dynamics of the In-Wheel Motor System," in IEEE Transactions on Vehicular Technology, vol. 61, no. 8, pp. 3510-3518, Oct. 2012, doi: 10.1109/TVT.2012.2207414.

27. X. Shao, F. Naghdy and H. Du, "Enhanced ride performance of electric vehicle suspension system based on genetic algorithm optimization," 2017 20th International Conference on Electrical Machines and Systems (ICEMS), 2017, pp. 1-6, doi: 10.1109/ICEMS.2017.8056265.

28. B. Németh, D. Fényes, P. Gáspár and J. Bokor, "Trajectory tracking based on independently controlled variable-geometry suspension for in-wheel electric vehicles," 2016 IEEE 55th Conference on Decision and Control (CDC), 2016, pp. 1570-1575, doi: 10.1109/CDC.2016.7798489. 
29. O. Deisser, G. Kopp, A. Fridrich and J. Neubeck, "Development and realization of an in-wheel suspension concept with an integrated electric drive," 2018 Thirteenth International Conference on Ecological Vehicles and Renewable Energies (EVER), 2018, pp. 1-8, doi: 10.1109/EVER.2018.8362366.

30. Y. Zhu, C. Zhao, J. Zhang and Z. Gong, "Vibration Control for Electric Vehicles With In-Wheel Switched Reluctance Motor Drive System," in IEEE Access, vol. 8, pp. 7205-7216, 2020, doi: 10.1109/ACCESS.2020.2964582.

31. H. Qiu, S. Liang, Z. Qi and H. Qin, "A novel design of an in-situ steering for a 4-wheel independent steering in a 4-in-wheelmotor Drive Electric Vehicle," 2012 19th International Conference on Mechatronics and Machine Vision in Practice (M2VIP), 2012, pp. 42-45.

32. S. Ren, H. Qiu, Z. Dong and Z. Qi, "An Inverse kinematics analysis for a four in-wheel-motor drive and all-wheel independent steering electric vehicle," 2012 19th International Conference on Mechatronics and Machine Vision in Practice (M2VIP), 2012, pp. 46-50.

33. Ahmad, X. Ge and Q. -L. Han, "Decentralized Dynamic Event-Triggered Communication and Active Suspension Control of InWheel Motor Driven Electric Vehicles with Dynamic Damping," in IEEE/CAA Journal of Automatica Sinica, vol. 8, no. 5, pp. 971-986, May 2021, doi: 10.1109/JAS.2021.1003967.

34. Zaremba, A., Hampo, R., and Hrovat D., 1997, "Optimal Active Suspension Design Using Constrained Optimization", Journal of Sound and Vibration, Vol. 207, No. 3, pp. 351-364.

35. Wong, J.Y., 1998, “Theory of Ground Vehicles”, John Wiley and Sons Inc., New York.

36. Pratt, R, “Flight Control Systems: Practical Issues in Design and Implementation”, IEE Publishing, p.131.

37. Abdussalam Ali Ahmed and Başar Özkan, "Stability And Dynamic Control Of Four In-Wheel Motored Vehicle Using Fuzzy PID Controller", International Journal of Mechanical \& Mechatronics Engineering IJMME-IJENS, Vol:16 No:03. June 2016.

38. Ravi, Srivel, Arokiaraj David, and Mohammed Imaduddin. "Controlling \& calibrating vehicle-related issues using RFID technology." International Journal of Mechanical and Production Engineering Research and Development 8.2 : 1125-1132.

39. Gopalakrishna, H. D., et al. "Crashworthiness of automobile in a vehicle-to-pole crash simulation." Int J Automob Eng Res Dev 4.2: 1-10.

40. Zabbar, Md Ajijul Bin, and Chisty Nafiz Ahmed. "Design \& Implementation of an Unmanned Ground Vehicle (UGV) Surveillance Robot." International Journal of Electrical and Electronics Engineering (IJEEE) 5.6: 22789944.

41. Bakar, Mashitah Abu, and Jamali Md Sah. "Dynamic Response Analysis for Development of Flexible Lightweight Vehicle Chassis Using CAE Tools." International Journal of Mechanical Engineering (IJME) 7.3: 9-20. 
